\title{
Expression and distribution of S-100, CD83 and apoptosis-related proteins (Fas, FasL and Bcl-2) in tissues of thyroid carcinoma
}

\author{
W. Xu, ${ }^{1}$ X. Li, ${ }^{1}$ S. Chen, ${ }^{2}$ J. Huang, ${ }^{1}$ S. Lin, ${ }^{1}$ J. Lin, ${ }^{1}$ Y. Li, ${ }^{1}$ X. Tan ${ }^{1}$ \\ ${ }^{1}$ The First Affiliated Hospital of Shantou University Medical School, Guangdong, Shantou; ${ }^{2}$ The Second \\ Affiliated Hospital of Shantou University Medical School, Guangdong, Shantou, China
}

il

(C)2008 European Journal of Histochemistry

Previous studies have shown that dendritic cells (DCs) and apoptosis play a critical role in the pathogenesis of thyroid carcinoma (TC). This study was designed to investigate the expression and distribution of S-100 protein, CD83 and apoptosis-related proteins (Fas, FasL and $\mathrm{Bcl}-2$ ) in the thyroid tissues of thyroid papillary carcinoma (TPC) and their role in TPC pathogenesis. Immunohistochemical staining techniques and other methods were used on pathological tissues of 30 patients with Thyroid papillary carcinoma (TPC) and 30 cases of thyroid follicular adenoma (TFA, as control) to detect the expression and distribution of S-100 protein , CD83, Fas, FasL and Bcl-2. A higher expression of S-100 protein in TPC $(4.6 \pm 3.2 \%)$ vs. TFA $(0.95 \pm 0.64 \%)(p<0.001)$ was observed as well as a higher expression of CD83 in the peri-cancerous tissues (PCT) $(32.51 \pm 22.32) \quad$ vs. TFA $(5.19 \pm 8.08)(p<0.001)$, oppositely, CD83 was negative in the cancerous net. TPC showed greater increases in levels of Fas, FasL and Bcl-2 than did the TFA. Our findings suggest that impaired immune function, absence of CD83-positive mature and activated dendritic cells in cancer nodules may have a role in the pathogenesis of thyroid papillary carcinoma. The regulation of Fas, FasL and Bcl-2 in TPC may help them evade the immune system.

Key words: thyroid papillary carcinoma (TPC) S-100 protein, CD83, apoptosis-related proteins, immunohistochemistry.

Correspondence: Wencan Xu,

The First Affiliated Hospital of Shantou University Medical School, Changping Road, Shantou 515041,

Guangdong Province, China

Tel. 86.754.8905428.

Fax: 86.754.8259850.

E-mail: xuwcan@163.com

Paper accepted on June 6, 2008

European Journal of Histochemistry

2008; vol. 52 issue 3 (July-September): 153-162
7 he immune system plays a key role in the onset and development of autoimmune thyroid diseases (ATDs) and the thyroid carcinoma (TC). Dendritic cells (DCs) are the most potent antigen presenting cells (APCs) which can induce the primary immune responses both in vitro and in vivo (Zhu et al. 1997). Anti-tumour immunity is coordinated by both innate and adaptive immunity, and mainly mediated by cytotoxic T cells (CTLs), natural killer (NK) cells and natural killer T (NKT) cells. The main players within this context are dendritic cells (DCs), which induce, coordinate and regulate the system (Banchereau et al. 2000). DCs are highly potent antigen-presenting cells (APCs) with the unique ability of taking up and processing antigens in the peripheral blood and tissues. They subsequently migrate to the draining lymph nodes, where they present antigens to naïve $\mathrm{T}$ lymphocytes, and thus induce a cellular immune response involving both $\mathrm{CD}^{+} \mathrm{T}$ helper 1 (ThI) cells and cytotoxic $\mathrm{CD8}^{+} \mathrm{T}$ cells. Moreover, DCs are also important in inducing humoral immunity as explained by their capacity to activate naïve and memory B cells (Jego et al. 2003). In addition, NK (Fernandez et al. 1999) and NKT cells (Kadowaki et al. 2001) may also be activated by DCs. Thus, DCs can modulate the whole immune repertoire, thereby representing an excellent tool for immunization against cancer. Consequently, DCs play a key role in the initiation and development of TC, studies have confirmed the protective role of $D C$ against thyroid tumors (Ugolini et al. 2007; Schott 2006; BachleitnerHofmann et al. 2006); Besides, mature DCs (CD83 positive) can activate $B$ cells effectively, which can stimulate the B cells motivation and differentiation, and then produce antibodies; Moreover, DCs also have the ability to produce cytokines and chemokines, which are the primary factor to prevent the initiation and development of TC. We speculate that the immune response defects or an impaired function of DCs, such as DC maturation 
defects may have a role in the pathogenesis of thyroid carcinoma.

The Fas/FasL system is one of an expanding family of receptor-ligand pairs involved in cell fate determination in a variety of cells (Nagata et al. 1995). When FasL binds to Fas on Fas-sensitive target cells, the target cells die by apoptosis (Nagata et al. 1995). FasL expression in non-lymphoid tissue is important for protecting immune privileged sites from immune-mediated damage (Griffith et al. 1995; Zhang et al. 2005). On the other hand, the Bcl-2 protooncogene is the prototype of a family of genes that inhibit apoptotic cell death induced by various stimuli, such as growth factor deprivation (Cory et al. 1995).

There is considerable evidence that Fas/FasLmediated apoptosis plays an important role in the pathogenesis of PTC (Erdogan et al. 2007). Also, $\mathrm{BCl}-2$ is involved in the regulation of apoptosis and may thus be involved in the pathogenesis of PTC.

Nowadays, It is known that $\mathrm{S}-100$ protein is a non-specific marker of DCs and CD83 antigen is a specific marker of activated and mature human DCs; both have been used to identify DCs. The S-100 marker has been examined extensively in TC, Study (Kilicarslan et al. 2000) has shown an increased expression of S-100 in thyroid carcinoma and S100 protein expression could be helpful in the diagnosis of thyroid carcinoma, but little is known about the expression and distribution of CD83 antigen in the thyroid tissues of thyroid carcinoma. Papillary thyroid cancer (PTC) is the most common variant of thyroid carcinoma. This study used immunohistochemical methods to follow the expression and distribution of S-100 protein, CD83 and apoptosisrelated proteins (Fas, FasL and $\mathrm{BCl}-2$ ) in thyroid tissues of TPC and to determine the role of DCs and apoptosis in the pathogenesis of TPC and to find possible connections between them.

\section{Materials and Methods}

\section{Subjects and thyroid tissues}

30 TPC patients (females, aged 31-63 years) were involved in this study. Normal thyroid tissues adjacent to thyroid follicular adenoma (TFA), obtained from 30 subjects with TFA (females, aged 26-60 years), were assigned as the control. The patients were admitted to the First Affiliated Hospital of Shantou University Medical School between 2001 and 2006, Diagnosis was made from physical examination of the patients and laboratory testing and confirmed by histological examination (hematoxylin and eosin staining) of the thyroid tissue samples. Informed consent was given by all of the patients and control sudjects after explaining the nature and purpose of the study. The thyroid tissue specimens were collected during surgical operation. All samples were fixed in 10\% buffered formalin, embedded in paraffin, and cut into $4 \mu \mathrm{m}$ sections.

\section{Enrichment of DCs from peripheral blood}

DCs were enriched from peripheral blood exactly according to the methods described (Zhu et al. 1997; Zhang et al. 2000; Kilicarslan et al. 2000; Li et al. 2001; Lutz et al. 1999; Chen et al. 2000). In short, peripheral blood mononuclear cells collected from heparinized fresh blood by centrifuging on a column of Ficoll-Hypaque (Sigma) were suspended in RPMI 1640 (Sigma) plus 10\% fetal calf serum, adhered on plastic surface for $2 \mathrm{~h}$. After depleting out the nonadherent cells by gentle washing, the adherent cells were cultured for an additional 7 days with granulocyte monocyte colony stimulating factor (GM-CSF) (800 units $/ \mathrm{mL}$, Pharmingen) and recombinant human IL-4 (500 units/mL, Pharmingen). This procedure reproducibly gave growing DC aggregates at 5-7 days, which were dislodged by gentle pipetting.

\section{Flow cytometry}

On the $7^{\text {th }}$ day, DCs were harvested. The percentage of CD83-positive DCs in the DC population was estimated by flow cytometry. The DCs were suspended in a solution of PBS, $1 \%$ fetal calf serum, and $0.1 \%$ sodium azide with saturating amounts of fluorescein isothiocyanate-conjugated mouse monoclonal antibody to human CD83 (HB15e; BD Pharmingen) or isotype matched controls for 30 minutes at $4^{\circ} \mathrm{C}$ after two washes in fresh buffer, the percentage of CD83-positive DCs was estimated on a FACStarpl (Beckton Dickinson) after removing the dead cells and contaminating lymphocytes.

\section{Immunohistochemical staining}

Immunohistochemical staining was used to detect S-100 protein, Fas, Fas L and Bcl-2. Tissue sections were firstly incubated in PBS containing the primary antibody (Rabbit anti-human polyclonal antibody to S-100 protein, PharMingen International, CA); Fas (Sc-714-G, Santa Cruz); FasL (Sc-534- 
G, Santa Cruz); or mouse anti-human monoclonal antibody to $\mathrm{Bcl}-2$ (Sc-509, Santa Cruz) at $4^{\circ} \mathrm{C}$ overnight, followed by incubation with Biotinlabelled secondary antibody for $\mathrm{Ih}$ and then with $A B C$ complex for 30 mins. The sections were developed in $D A B$ and then mounted and observed under a microscope. A known sample from a patient with breast cancer was used as a positive control, and PBS was used instead of the primary antibody as the negative control. The staining of CD83 was performed as described by Chen et al. with some modifications (Chen et al. 2000; Banchereau et al. 1998; Xu et al. 2007). Formalin-fixed, paraffinembedded thyroid specimens were washed three times in PBS and treated with pepsin $0.5 \%$ in $0.01 \mathrm{~N} \mathrm{HCl}$ ) for 20 mins at $37^{\circ} \mathrm{C}$ before staining for CD83. The specimens were then treated with normal goat serum for 20 mins to block non-specific binding. Mouse anti-human monoclonal antibodies as primary antibody (Pharmingen), diluted $1: 100$, were then added and incubated over night. The sections were washed $3 x$ with PBS and reincubated with biotinylated goat anti-mouse immunoglobulin (1:200, DAK0, Denmark) at room temperature for $\mathrm{lh}$. After a wash in PBS, sections were soaked in alkaline phosphatase-conjugated streptavidin (DAKO) and washed. New Fuchsin (DAKO) was then used as chromogen. Hematoxylin was used as a counter stain. A known sample from a patient with hepatocellular carcinoma was used as a positive control; negative control slides were processed with PBS instead of the primary antibody, but included all other steps of the procedure.

\section{Positive staining estimation}

Expression of S-100 protein was noticed in the nucleus and/or in the cytoplasm of DCs, appearing as brown granules, and the expression levels were stronger than background staining. Expression of Fas, FasL and Bcl-2 protein was seen on the membrane and/or in the cytoplasm of thyroid follicular cells or cancer cells. Expression of CD83 showing as red granules was observed on the membrane and/or in the cytoplasm of DCs. CD83 positive cells were counted over the whole specimens. The intensity of positive staining of S-100 was evaluated subjectively by 2 independent observers using a 10x lens in 10 randomly selected fields of each specimen. Each observer made an average of the percentages of the 10 fields and then the mean of the two scores was made. Positive staining of Fas, Fas L and $\mathrm{Bcl}-2$ protein in thyrocytes or cancer cells is expressed as the percentage of positive thyrocytes or cancer cells to the total number of thyrocytes or cancer cells in each field.

S-100 protein-positive cells are shown as the ratio of a total of 100 infiltrating cells. the frequencies of $\mathrm{CD} 83^{+}$cells are shown as total number of positive cells/specimen.

\section{Statistical analysis}

The data are expressed as mean \pm SD. The statistical analysis was done by unpaired or paired $t$ tests. Positivities for S-100 and CD83 in TPC and TFA are shown as percentages, and comparisons were made by the $\chi^{2}$ test. P-values less than 0.05 are considered to indicate statistical significance. The SPSS 11.0 statistical program was used for the calculations.

\section{Results}

\section{Percentage of CD83-positive DCs in blood from patients with TPC and TFA}

After 7 days of culture under GM-CSF and IL-4, the cells exhibited DC morphology with veiled process and dendrites. These results showed that the enriched cells were morphologically compatible with DCs. The percentages of CD83-positive DCs in TPC were $4.68 \pm 1.26 \%($ mean $\pm S D, n=5)$ of the total DCs enriched from peripheral blood by using GM-CSF and IL-4 similar to TFA $(5.09 \pm 1.47 \%$, $n=5, p>0.05$ ) (Figure 1).
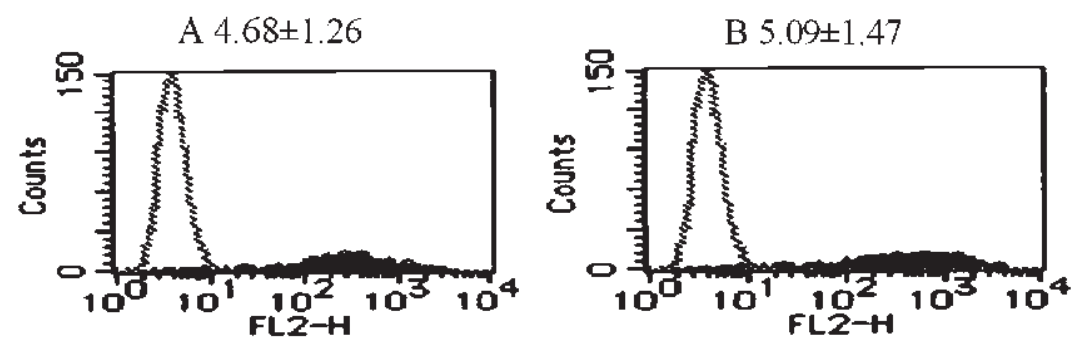

Figure 1. CD83 of TPC(A) and CD83 of control (B). 


\section{Expression of S-100 protein}

The distribution of S-100 protein was detected in the nucleus and cytoplasm. S-100 protein was positive in all thyroid tissues, Prevalences of the two groups were all $100 \%$. TFA tissue seldom expresses S-100 protein $(0.95 \pm 0.64 \%$, Figure $2 A)$, Compared with TFA, the expression of S-100 protein in TPC was elevated $(4.6 \pm 3.2 \%$, Figure $2 \mathrm{~B}$ and Table 1). $(p<0.001)$.
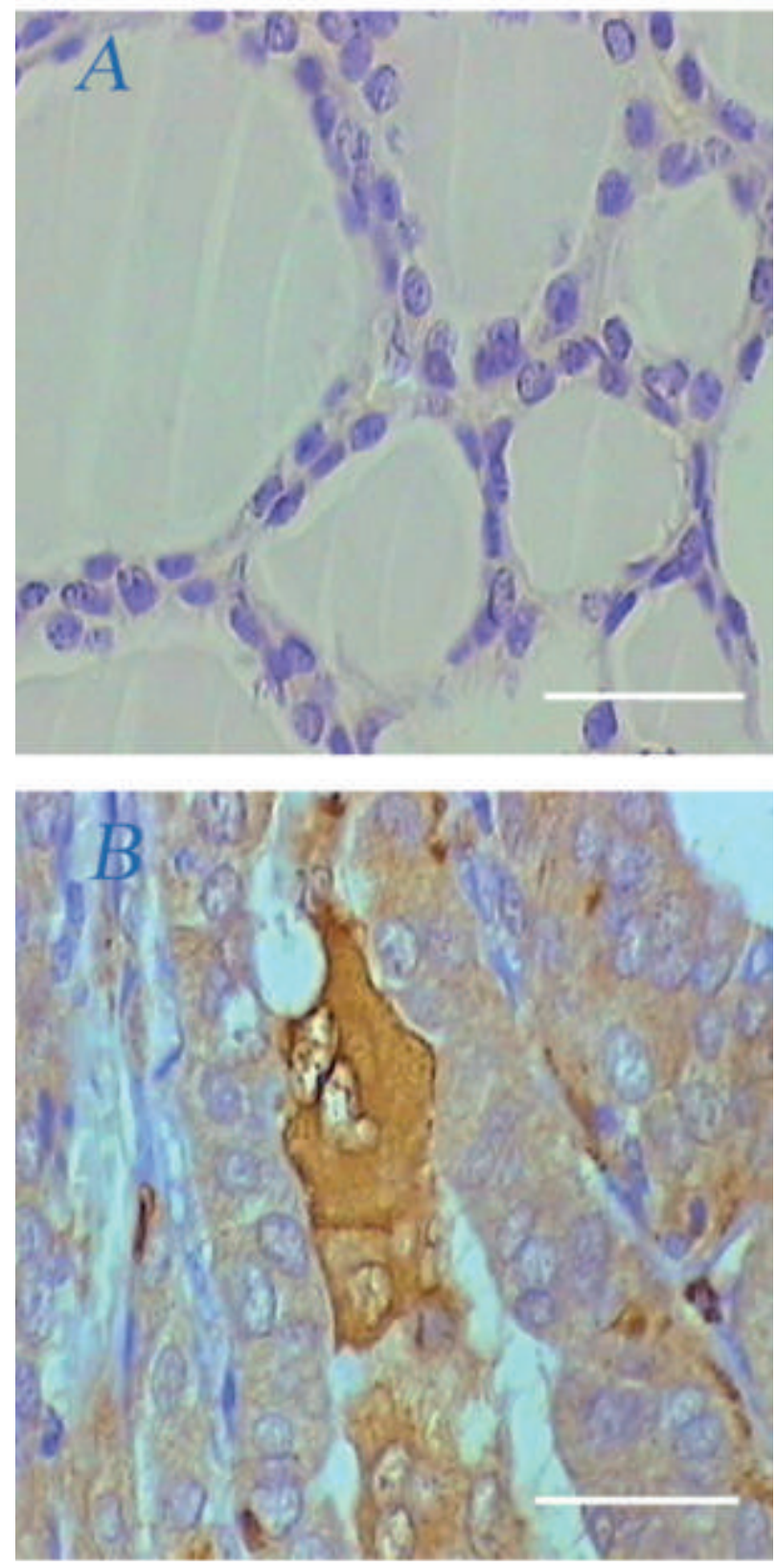

Figure 2. Expression of S-100 protein in TFA (A) and TPC (B); bar $=\mathbf{3 0} \mu \mathrm{m}$.
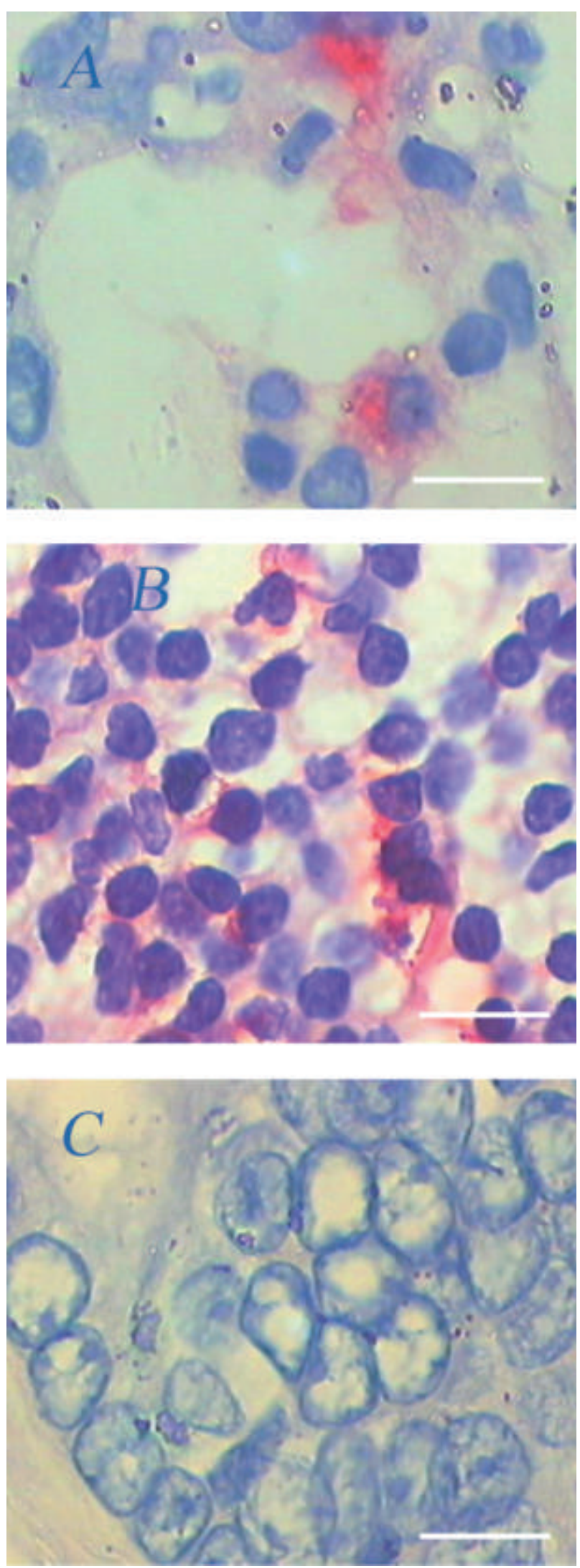

Figure 3. Expression of CD83 in TFA (A), PCT (B), and TPC (C); bars $=\mathbf{1 0} \mu \mathrm{m}$. 


\section{Expression of CD83}

The CD83 positive DCs were also distributed in infiltrating lymphocytes, CD83 was expressed in the cytoplasm. CD83 seldom expressed in TFA tissues (with Prevalences of $30 \%$, Frequencies 5.19 \pm 8.08 , Figure 3A). The CD83-positve cells were detected in infiltrating cells in peri-cancerous tissue (PCT) (with Prevalences of $73 \%$, Frequencies 32.51 \pm 22.32 Figure 3B).

CD83-positive cells in TPC could only be dispersedly detected around cancer nodules, but there were no CD83-positive activated DCs in cancer nodules from any cases with TPC (Figure $3 \mathrm{C}$ ) (Table 2).

\section{Expression of Fas, FasL and Bcl-2}

All samples expressed Fas, mainly on the cell surface and cytoplasm (Figure 4 A, D). TFA thyrocytes expressed moderate Fas (Figure 4 A) and minimal FasL(Figure 4 B). TPC cancer cells expressed higher Fas, Fas L and $\mathrm{Bcl}-2$ than did TFA thyrocytes (Figure $4 \mathrm{~A}-\mathrm{F})(p<0.05)$ (Table 3 ).

\section{Discussion}

Tumors can escape the host immunity surveillance because tumor cells cannot express the information molecule required by the host immunity system. The immunoreactions in the host are to capture its antigen by APC. After processing, the antigen information is present in $\mathrm{T}$ and $\mathrm{B}$ lymphocytes, stimulating a series of specific cellular immunologic response and humoral immunoresponse. It is, therefore, directly related with the induction of immunological activation or immunological tolerance, and the key to the process is APC. DCs are a kind of the strongest APCs in which antigen processes and functions (Hart 1997; Inaba 1997), and can stimulate the native T cells. DCs are in a unique state of immune response. DCs capture antigens at the periphery, process those into antigenic epitope at the lymphoid tissues and become activated. The activated DCs migrate from the lymphoid tissues into target organs via blood or lymph and induce the production of activated lymphocytes. Activated DCs also produce many cytokines and chemokines, which are essential for the functioning and survival of activated lymohocytes. Due to a lack of a human DC-specific marker, S100 protein-positive cells, interdigitating cells (IDC) and HLA-DR
Table 1. S-100 expression in group of TFA, TPC.

\begin{tabular}{lccc}
\hline Group & Number & Prevalences $(\%)$ & Percentage $(X \pm S D)(\%)$ \\
\hline TFA & 30 & 100 & $0.95 \pm 0.64$ \\
TPC & 30 & 100 & $4.6 \pm 3.2$ \\
\hline
\end{tabular}

TPC compared with TFA, $p<0.001$

Table 2. CD83 expression in group of TFA, TPC.

\begin{tabular}{lccc}
\hline Group & Number & revalences $(\%)$ & Percentage $(X \pm S D)(\%)$ \\
\hline TFA & 30 & $9 / 30(30)$ & $5.19 \pm 8.08$, \\
PCT & 30 & $22 / 30^{*}(73)$ & $32.51 \pm 22.32^{\triangle}$ \\
TPC & 30 & 0 & 0 \\
\hline
\end{tabular}

PCT compared with TFA, ${ }^{*} p<0.05,{ }^{\Delta} p<0.001$. Prevalence is shown as the number of cases positive for CD83-positive DCs. Frequency indicates the actual number of CD83positive DCs in the whole specimen.

Table 3. Staining intensity of Fas,FasL and Bcl-2 in group of TPC and TFA $(n=30)$ groups.

\begin{tabular}{lccc}
\hline Group & Fas & FasL & Bcl-2 \\
\hline TFA & $35.75 \pm 12.89$ & $26.08 \pm 20.73$ & $14.80 \pm 21.26$ \\
TPC & $55.43 \pm 10.81^{*}$ & $64.74 \pm 14.84^{*}$ & $61.51 \pm 20.32^{* *}$ \\
\hline
\end{tabular}

*Compared with TFA, $p<0.05,{ }^{* *}$ Compared with TFA, $p<0.01$.

positive cells have been studied as functional DCs in different pathological conditions (Demetris et al. 1998; Ishigami et al. 1998; Gabrilovich et al. 1997; Steinman 1991; Hart 1997). But, recent advances in DC research indicate that IDC probably represent a population of DCs undergoing apoptosis and DCs expressing HLA- DR without co-stimulation would only induce $T$ cells energy, but not $T$ cell stimulation, whereas, there is no known function of S100-positive cells (Hart et al. 1997; Chen et al. 2004). In addition, $T$ cell activation requires engagement of co-stimulatory receptors on the $T$ cells. DCs are at the center of the developing tumorspecific immune response, and are involved both in the initiation of tumor-specific immunity and the generation of immune effective functions (Pfragner et al. 2005; Schott et al. 2004). Many observations have suggested that DCs in tumors are functionally impaired (Woods et al. 2000; Avigan. 1999; Zhang et al. 2000, 2002; Li et al. 1999).

Previous studies had showed that DCs were not only related to the development of autoimmune dis- 

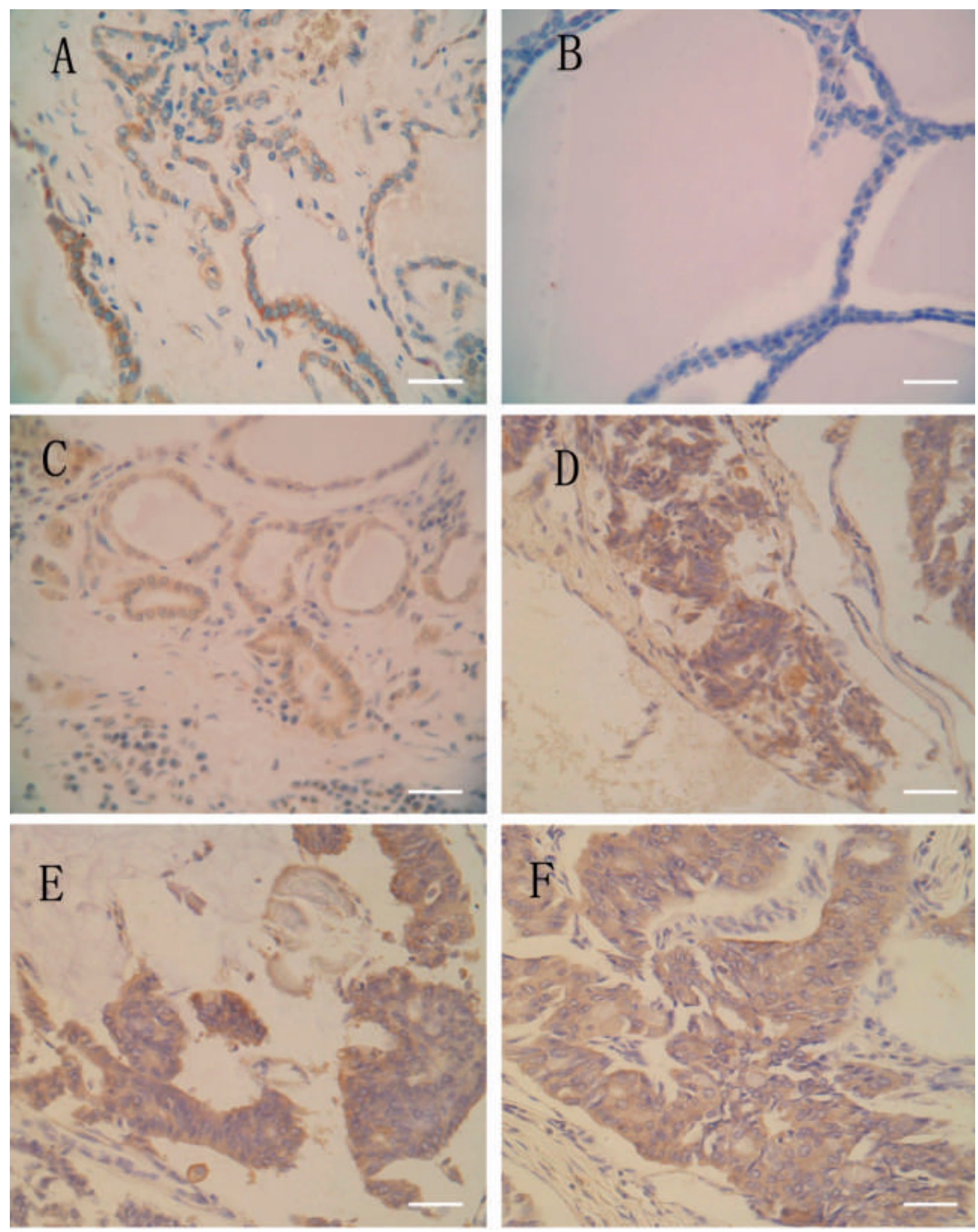

Figure 4. Expression of Fas (A), FasL (B) and Bcl-2 (C) in TFA; expression of Fas (D), FasL (E) and Bcl-2 (F) in TPC; bars = $50 \mu \mathrm{m}$. 
orders but also the development of cancer. Infiltrating DCs were frequently observed in papillary carcinoma and Hashimoto's disease, and these DCs were composed primarily of IDCs. The number of DCs was closely correlated with the expression of thyrocytes for S-100 protein and Ia-antigen. These findings suggest that DCs may play an important role in the immunologic defence mechanisms against papillary carcinomas and in the progression and self-perpetuation of autoimmunity (Yamakawa $\mathrm{M}$ et al. 1993). Our previous work (Xu et al. 2004; $\mathrm{Xu}$ et al. 2007) focusing on the expressions of S100 protein and CD83 in the thyroid tissues of autoimmune thyroid diseases (ATDs) illustrated higher expression of S-100 in HT and GD than in TFA as well as stronger expression of CD83 in HT and GD than in TFA. Our findings suggest that high expression of DCs' markers may be related to the pathogenesis of HT and GD. Up-regulation of both the number and matured functions of DCs may lead to the presentation of more antigens to lymphocytes which are related to the development of ATDs. Our present study detected the expression and distribution of S-100 protein and CD83 in tissues of TPC and TFA. The results showed a higher expression of S100 protein in TPC vs TFA. The finding gave us some evidence that higher number of DCs is related to the development of TPC. Studies had showed that increased expression of S100 protein had been found in the tissue of breast cancer, gastric cancer, esophageal carcinoma (EC) and colon carcinoma (Ilg et al. 1996; Stulk et al. 1999; Yinemura et al. 2000; Rudland et al. 2000), and were related with the prognoses of these cancers, and the higher expression of S100 protein in cancer tissues is related with the infiltration of cancer cell (Rustandi et al. 2000). Our study showed an increased number of S-100-positive DCs in TPC similar to the result of our previous studies in which we found an increased number of S-100-positive DCs in HT and $G D$, but the number of CD83-positive DCs (mature and motivated DCs) is absent in cancer net which is opposite to the result of our previous studies in which an increased number of CD83-positive DCs in $H T$ and GD was found.

Nowadays, CD83 positive DCs have been considered as mature and activated dendritic cells which can also express high level of co-stimulatory factors (such as CD80 and CD86), these CD83 positive DCs possess very powerful antigen presenting ability (Pesce et al. 2002). Lower expression of
CD83, CD80 and CD86 was found in EC-DCs (Zhang et al. 2000). The importance of DC83 and the CD80/CD86-CD28 system in $T$ cell responses has been well demonstrated (Avigan. 1999; Zhang et al. 2000; Chen et al. 2004; Mogi et al. 2000). The CD80 and CD86, members of the immunoglobulin super gene family, are encoded by separate genes and provide co-stimulatory function for APCdependent T-cell activation both in vivo and in vitro (Zai et al. 2001; Zhang et al. 2000; Zhang et al. 1998; Ito et al. 2001 ; Xing et al. 2000). A previous study reported that most tumor tissues did not express co-stimulatory molecules, which would render $T$ cells unresponsive for the specific antigens (Avigan 1999). Because CD83 positive DCs were not detected in most of the TFA, their existence in the tissues from TPC patients indicated the maturation and activation of immature DCs. To see if the number of CD83-positive DCs also increases in the peripheral blood, we carried out a flow cytometric analysis to estimate the frequencies of CD83 positive DCs in the peripheral blood. We found almost similar frequencies of CD83-positive DCs in peripheral blood from TPC and TFA. The similar frequencies of CD83-positive DCs in TPC and TFA implies that the activation and maturation of DCs occur only locally in the thyroid tissue or in the neighbouring lymphoid organs of TPC, but not in the peripheral blood, and also implies that the increased number of CD83 positive DCs do not come from the peripheral blood. Although the exact significance of these findings remain to be clarified, an importance of tissue infiltrating DCs in these pathological conditions of TPC is now evident. Most strikingly, all CD83-positive DCs were localized in the pericancerous tissues, and there were no CD83positive DCs in any cancer nodules. It appears to be unclear that absence of CD83 positive DCs in cancer nodules is the cause or result of cancer development. We speculate that there are some elements within or around the cancer nodules which do not favour the maturation or motivation of DCs or even the survival of DCs.

There are conflicting reports about the prevalence of activated CD83-positive DCs in cancers, Enk et al. (1997) have reported that DCs isolated from metastatic melanoma tissue contained very few activated DCs, whereas Thrunher et al. (1996) documented substantial number of CD83-positive DCs from renal cell carcinoma. Both of these investigators have isolated DCs following mechanical 
disruption of the cancer specimens, indicating that DCs in their experiments may have come from cancerous tissues or from adjacent non-cancerous tissues. Similar to our data, absence or minimal recruitment of CD83-positive DCs has been shown in prostate cancer (Troy et al. 1998), renal cell cancer (Troy et al. 1998) and hepatocellular carcinoma (Chen et al. 2000).

What is the significance of the absence of activated DCs in cancer nodules form patients with TPC? Activated DCs present the antigenic epitope to $T$ cells and induce its activation, which are the most strong inducers for IL-12 and specific cytotoxic TI lymphocytes during carcinogenesis (Fan et al. 2002; Hao et al. 2002). In the absence of activated DCs in cancer nodules, normal immune surveillance against TPC may be hampered due to defective production of tumor-specific lymphocytes. Again, tumor-specific lymphocytes would not be able to function and survive in the absence of activated $D C s$.

Studies have shown that Fas/FasL mediated apoptosis also play an important role in the pathogenesis of TPC (Erdogan et al. 2007). By formation of a death-inducing signaling complex and initiation of a signaling cascade of caspases, Fas ligand (FasL) induces apoptosis of Fas-expressing cells (Thome et al. 2001; Budd et al. 2006). We studied the role of the apoptosis-related molecules Fas, FasL and Bcl-2 in TPC.We found that TPC cancer cells expressed higher level of Fas, FasL and $\mathrm{Bcl}-2$ than did TFA thyrocytes. The high level of FasL was found in TPC, suggesting that it helps them escape immune surveillance by eliminating infiltrating lymphocytes. Increased level of $\mathrm{Bcl}-2$ may render TPC cancer cells resistant to Fas/FasLmediated elimination and may thus be involved in the pathogenesis of TPC. Purtianko et al. (2003) studied the Fas/FasL system in the regulation of tumor-immune system interactions in papillary thyroid carcinoma and found that Positive staining for Fas L was observed on neoplastic thyrocytes, whereas staining of normal thyroid cells was weak or absent. Staining of lymphocytes both in tumor tissue and in lymph nodes for FasL was weak or absent. Fas expression was found on normal thyroid cells, cancer cells and lymphocytes both in tumor and in lymph nodes with metastases. In lymph node metastases, in lymphocytes adjacent to Fas L cancer cells morphological signs of apoptosis were observed. Their findings suggested that Fas/FasL system favour the survival of cancer cells in TPC.

In summary, the complete absence or minimal recruitment of CD83-positive DCs in cancer nodules indicates a role of CD83-positive activated DCs in the pathogenesis of TPC. The regulation of Fas, FasL and $\mathrm{Bcl}-2$ in TPC may help them evade the immune system.

\section{Acknowledgements}

We thank Dr. Fu Yucai for excellent technical assistance.

\section{References}

Avigan D. Dendritic cells: development, function and potential use for cancer immunotherapy. Blood Rev 1999;13:51-64.

Bachleitner-Hofmann T, Strohschneider M, Krieger $P$, Sachet M, Dubsky $\mathrm{P}, \mathrm{Hayden} \mathrm{H}$, et al. Heat shock treatment of tumor lysatepulsed dendritic cells enhances their capacity to elicit antitumor T cell responses against medullary thyroid carcinoma. J.Chin Endocrinol Metab 2006;91:4571-7. Epub 2006 Sep 5.

Banchereau J, Steinman RM. Dendritic cells and the control of immunity. Nature 1998:392:245-52.

Banchereau J, Briere F, Caux C, Davoust J, Lebecque S, Liu YJ, et al. Immunobiology of dendritic cells. Annual Review of Immunology 2000;18: 767-811.

Chen S, Akbar SM, Tanimoto K, Ninomiya T, Iuchi H, Michitaka K et al. Absence of CD83-positive mature and activated dendritic cells at cancer nodules from patients with hepatocellular carcinoma: relevance to hepatocarcinogenesis. Cancer Letters 2000;148: 49-57.

Budd RC, Yeh WC, Tschopp J. cFLIP regulation of lymphocyte activation and development. Nat Rev Immuno 2006;6:196-204.

Chen SR, Lou YP, Zhang JK, Yang W, Zhen ZC, Chen LX, et al. The Study on immune function of dendritic cells in patients with esophageal carcinoma. World J Gastroenterol 2004;10:934-9.

Cory S. Regulation of lymphocyte survival by $\mathrm{Bcl}-2$ gene family. Annu Rev Immunol 1995;13:513-43.

Demetris AJ, Sever C, Kakizoe S, Oguma S, Starzl TE, Jaffe R. S100 protein-positive dendritic cells in primary biliary cirrhosis and other chronic inflammatory liver diseases, Relevance to pathogenesis. Am J Pathol 1998;134:741-7.

Enk $A H$, Jonuleit $H$, Saloga J, Knop J. Dendritic cells as mediators of tumor-induced tolerance in metastatic melanoma. Int $\mathrm{J}$ Cancer 1997;73:309-16.

Erdogan M, Karadeniz M, Berdeli A, Tamsel S, Ertan $\mathrm{Y}$, Uluer $\mathrm{H}$, et al. Fas/Fas ligand gene polymorphism in patients with papillary thyroid cancer in the Turkish population. J Endocrinol Invest 2007;30:4116.

Fan P, Wu ZY, Wang S. An investigation on the phenotype of cultured dendritic cells from the peripheral blood of patients with breast cancer. J NanJing Med Univ 2002;16:115-8.

Fernandez NC, Lozier A, Flament C, Ricciardi-Castagnoli P, Bellet D, Suter $M$, et al. Dendritic cells directly trigger $\mathrm{NK}$ cell functions: cross-talk relevant in innate anti-tumor immune responses in vivo. Nature Medicine 1999;5:405-11.

Gabrilovich DI, Corak J, Ciernik IF, Kavanaugh D and Carbone DP. Decreased antigen presentation by dendritic cells in patients with breast cancer. Clin Cancer Res 1997:3:483-90.

Griffith TS, Brunner T, Fletcher SM, Green DR, Ferguson TA. Fas ligand-induced apoptosis as a mechanism of immune privilege. Science, 1995;270:1189.

Hao MW, Liang YR, Liu YF, Liu L, Wu MY, Yang HX. Transcription factor EGR-1 inhibits growth of hepatocellular carcinoma and esophageal carcinoma cell lines. World J Gastroenterol 2002;8: 203-7. 
Hart DNJ. Dendritic cells: unique leukocyte populations which control the primary immune response Blood 1997;90:3245-87.

Inaba K. Dendritic cells as antigen-presenting cells in vivo. Immnol Cell Biol 1997;75:206-8

Ilg EC, Schafer BW, Heizmann CW. Expression parttern of S100 calcium-binding proteins in human tumors. Int J Cancer 1996;68:32532.

Ishigami S, Aikou T, Natsugoe S, Hokita S, Iwashige H, Tokushige M, et al. Prognostic value of HLA-DR expression and dendritic cell infiltration in gastric cancer. Oncology 1998;55:65-9.

Ito $T$, Amakawa $R$, Inaba M, Ikehara $S$, Inaba K, Fukuhara S. Differential regulation of human blood dendritic cell subsets by IF Ns. Immunology 2001;104:2961-9.

Jego G, Palucka AK, Blanck JP, Chalouni C, Pascual V \& Banchereau J. Plasmacytoid dendritic cells induce plasma cell differentiation through type I interferon and interleukin 6. Immunity 2003; 19:225-34.

Kadowaki N, Antonenko S, Ho S, Rissoan MC, Soumelis V, Porcelli $\mathrm{SA}$, et al. Distinct cytokine profiles of neonatal natural killer T cells after expansion with subsets of dendritic cells. Journal of Experimental Medicine 2001;193:1221-6.

Kilicarslan B,Pesterelli EH,Oren N Sarqin FC, Karpuzoqlu G.Epithelial membrane antigen and S-100 protein expression in benign and malignant papillary thyroid neoplasms.Adv Clin Path 2000;4:155-8.

Li MS, Yuan AL, Zhang WD, Chen XQ, Zhang YL and Zhou DY. Study on immune function of dendritic cells in patients with colorectal neoplasms. Shijie Huaren Xiaohua Zazhi 1999;7:429-36.

$\mathrm{Li} Y Q$, Zeng BH. In vitro culture and anti-cancer immunity of dendritic cells. Chin J of Cancer Prev\&Treat 2001;8:78-80.

Lutz MB, Kukutsch N, Ogilvie AL, Rössner S, Koch F, Romani N, et al. An advanced culture method for generating large quantities of highly pure dendritic cells from mouse bone marrow. Journal of Immological Methods 1999;223:77-92.

Mogi S, Sakurai J, Kohsaka T, Enomoto S, Yagita H, Okumura K, et al. Tumour rejection by gene transfer of 4-1BB ligand into a CD80+ murine squamous cell carcinoma and the requirements of co-stimulatory molecules on tumor and host cells. Immunology 2000;101: 541-7.

Nagata S, Golstein P. The Fas death factor. Science 1995;267:144956.

Pesce G, Fiorino N, Riccio AM, Montagna P, Torre G, Salmaso C, et al. Different intrathyroid expression of intercellular adhesion moleculeI (ICAM-1) in Hashimoto's thyroiditis and Graves' disease: analysis at mRNA level and association with B7.1 costimulatory molecule. $\mathrm{J}$ Endocrinol Invest 2002;25:289-95.

Pfragner R, Skofitsch G, Hoger H, Jech M, Rinner B, Siegl V, et al. Medullary thyroid carcinoma: autologous tumor cell lines for dendritic cell vaccination. Anticancer Res 2005;25:4225-30.

Purtianko AS,Cherstvoi ED. The role of Fas/FasL system in the regulation of tumor-immune system interactions in papillary thyroid carcinoma in children and adolescents. Arkh Patol 2003;65:18-21.

Rudland PS, Platt Higgins A, Renshaw C, West CR, Winstanley JHR, Robertson $L$, et al. Prognostic significance of the metastasis-inducing protein $\mathrm{S} 100 \mathrm{~A} 4(\mathrm{p} 9 \mathrm{Ka})$ in human breast cancer. Cancer Res 2000;60:1595-603.

Rustandi RR, Baldisseri DM, Weber DJ. Structure of the negative regulatory domain of p53 bound to S100B(betabeta). Nat Struct Biol 2000;7:570-4.

Schott M. Immunesurveillance by dendritic cells: potential implication for immunotherapy of endocrine cancers. Endocr Relat Cancer 2006;13:779-95.

Schott M, Scherbaum WA. Immunotherapy and gene therapy of thyroid cancer. Minerva Endocrinol 2004;29:175-87.

Steinman RM. The dendritic,cell system and its role in immunogenicity. Annu Rev Immunol 1991;9:271-96.

Stulik J, Osterreicher J, Koupilova K, Knizek J, Macela A, bures J, et
al.The analysis of S100 A9 and S100 A8 expression in matched sets of macroscopically normal colon mucosa and colorectal carcinoma: the S-100 A9 and S-100 A8 positive cells underlie and invade tumor mass. Electrophoresis 1999;20:1047-54.

Thome M, Tschopp J. Regulation of lymphocyte proliferation and death by FLIP. Nat rev Immunol 2001;1:50-8.

Thurnher M, Radmayr C, Ramoner R, Ebner S, Bock G, Klocker H, et al. Human renal-cell carcinoma tissue contains dendritic cells. Int $J$ Cancer 1996;67:1-7.

Troy A, Davidson P, Atkinson C, Hart DNJ,. Phenotype characterisation of the dendritic cell infiltrate in prostrate cancer. J Urol 1998;160:214-9.

Troy A, Summers KL, Davidson PJT, Atkinson CJ, Hart DNJ. Minimal recruitment and activation of dendritic cells within renal cell carcinoma. Clin Cancer Res 1998;4:585-93.

Ugolini C, Basolo F, Projetti A, Vitti P, Miccoli P, Toniolo A. Lymphocyte and immature dendritic cell infiltrates in differentiated, poorly differentiated, and undifferentiated thyroid carcinoma. Thyroid. 2007;17:389-93

Woods GM, Doherty KV, Malley RC, Rist MJ, Muller HK. Carcinogenmodified dendritic cells induce immunosuppression by incomplete Tcell activation resulting from impaired antigen uptake and reduced CD86 expression. Immunology 2000;99:16-22.

Xing LH, Wang FS, Liu MX, Zhu CL. Dendritic cells and liver diseases. Shijie Huaren Xiaohua Zazhi 2000;8:1276-9.

Xu W, Chen S, Huang J, Zhang Z, Chen L, Zhang W. The expression and distribution of $S-100$ protein and $C D 83$ in thyroid tissues of autoimmune thyroid diseases. Cell Mol Immunol 2004;1:378-82.

Xu WC, Chen SR, Huang JX, Zheng ZC, Chen LX, Lin JJ, et al. Expression and distribution of S-100 protein, CD83 and apoptosisrelated proteins (Fas, Fas L and $\mathrm{Bcl}-2$ ) in the thyroid tissues of autoimmune thyroid diseases. European Journal of Histochemitry, 2007; 51:291-300

Yamakawa M, Kato H, Takagi S, Karube Y, Seki K, Imai Y.Dendritic cells in various human thyroid diseases. In Vivo 1993;7:249-56.

Yinemura Y, Endou Y, Kimura K, Fushida S, Bandou E, Taniguchi K, et al. Inverse expression of S100 A4 and Ecadherin is associated with metastatic potential in gastric cance. Clin Cancer Res 2000;6:4234-42.

Zai SH, Liu JB, Zhu P and Wang YH. The expression of CD80 and CD86 in hepatocarcinoma and cirrhosis tissues. J Fourth Mil Med Univ 2001;21:26-7.

Zhang $X Z$, An HL, Zhang XB. Immunohistochemical study of S-100 protein-positive dendritic cells in esophageal carcinoma. J Xi'an Med Univ 1998;19: 215-8.

Zhang XG, Gu ZJ, Qiu YH, Xie W, Wang YD, et al. The study of dendritic cells induced by cytokines from different adherent cells in vitro. Shanghai Immunology, J 2000;20: 140-4.

Zhang JK, Sun JL, Chen HB, Zeng Y, Qu YJ. Influence of granulocytemacrophage colony-stimulating factor and tumor necrosis factor on anti-hepatoma activities of human dendritic cells. World $\mathrm{J}$ Gastroenterol 2000;6:718-20.

Zhang JW, Xu J, Jia SS. Infiltration of dendritic cells into cervical lymph nodes in laryngeal carcinama. Chin J Otohinolaryngol 2000; 35:472-4.

Zhang JK, Li J, Chen HB, Sun JL, Qu YJ, Lu JJ. Antitumor activities of human dendritic cells derived from peripheral and cord blood. World J Gastroenterol 2002;8:87-90.

Zhang Zhenlin, LIN Bo, YU Luyang, GUO Lihe.CMV-hFasL transgenic mice prevent from experimental autoimmune thyroiditis. Chin Med $J$ (Engl) 2005;5:11.

Zhu XJ, Cao XT, Yu YZ, GY Chen, T Wan, SH Ma, et al. Generation of dendritic cells from human peripheral blood. Chin J Cancer Biother 1997;4:302-6.

Zoller M. Immunotherapy of cancer for the elderly patient: does allogeneic bone marrow transplantation after nonmyeloablative conditioning provide a new option? Cancer Immunol Immunother 2004; 53:659-76. 
W. Xu et al. 